\title{
Identification of in vivo mRNA targets of GLD-1, a maxi-KH motif containing protein required for C. elegans germ cell development
}

\author{
Min-Ho Lee and Tim Schedl ${ }^{1}$ \\ Department of Genetics, Washington University School of Medicine, St. Louis, Missouri 63110, USA
}

\begin{abstract}
Caenorhabditis elegans GLD-1, a KH motif containing RNA-binding protein of the GSG/STAR subfamily, controls diverse aspects of germ line development, suggesting that it may have multiple mRNA targets. We used an immunoprecipitation/subtractive hybridization/cloning strategy to identify $15 \mathrm{mRNAs}$ that are putative targets of GLD-1 binding and regulation. For one target, the rme-2 yolk receptor mRNA, GLD-1 acts as a translational repressor to spatially restrict RME-2 accumulation, and thus yolk uptake, to late-stage oocytes. We found that GLD-1 binds sequences in both 5' coding and the 3' untranslated region of rme-2 mRNA. Initial characterization of the other 14 targets shows that (1) they are coexpressed with GLD-1; (2) they can have mutant/RNA-mediated interference depletion phenotypes indicating functions in germ line development or as maternal products necessary for early embryogenesis; and (3) GLD-1 may coregulate mRNAs corresponding to functionally redundant subsets of genes within two gene families. Thus, a diverse set of genes have come under GLD-1-mediated regulation to achieve normal germ line development. Previous work identified tra-2 as a GLD-1 target for germ line sex determination. Comparisons of GLD-1-mediated translational control of rme-2 and tra-2 suggests that the mechanisms may differ for distinct target mRNA species.
\end{abstract}

[Key Words: Translational control; target mRNAs; maxi-KH; Caenorhabditis elegans; yolk receptor; germ line] Received June 1, 2001; revised version accepted June 18, 2001.

The germ line relies heavily on translational control as a mechanism for temporal/spatial regulation of gene expression (for reviews, see Wickens et al. 2000; DeMoor and Richter 2000). Because the genome is transcriptionally silent from late meiotic prophase (diakinesis), through the meiotic divisions/fertilization and into embryogenesis, translational control mechanisms are used to alter gene expression during this period. Translational regulation in the germ line also occurs during periods of active transcription (e.g., Crittenden et al. 1994).

Translational regulation uses sequences found in the $3^{\prime}$ untranslated region (UTR) and/or 5'UTR of the mRNA. Transacting factors that bind such regulatory sequences have been identified by molecular methods. For example, Bruno, identified by expression screening, binds the 3'UTR of osk mRNA to repress its translation before posterior localization in the Drosophila oocyte, whereas FBF-1 and FBF-2, identified by the yeast threehybrid system, bind the 3'UTR of fem-3 mRNA to re-

\footnotetext{
${ }^{1}$ Corresponding author.

E-MAIL ts@genetics.wustl.edu; FAX (314) 362-7855.

Article and publication are at http://www.genesdev.org/cgi/doi/10.1101/ gad.915901.
}

press the male sexual fate in the Caenorhabditis elegans hermaphrodite germ line (Webster et al. 1997; Zhang et al. 1997). However, genetic analysis indicates that Bruno and FBF-1/-2 must regulate additional mRNA targets because loss of either protein has a more pleiotropic mutant phenotype than misregulation of the target mRNA used in its identification. Thus, a comprehensive understanding of how such a translational regulator controls development requires first the identification of many of its mRNA targets. Subsequent work can provide information on the normal function of each target and the consequences of its misregulation in the mutant/ disease state. The availability of multiple mRNA targets will allow one to learn if different targets of a transacting factor are regulated by similar or distinct mechanisms.

GLD-1 is an RNA-binding protein that regulates multiple aspects of germ line development in C. elegans, suggesting that it regulates multiple RNAs. GLD-1 is a member of a family of proteins, including mouse Quaking, mouse/human SAM68, and Drosophila How, that share an $\sim 200$ amino acid region of similarity called the GSG or STAR domain (Jones and Schedl 1995; Vernet and Artzt 1997; DiFruscio et al. 1998). Within the conserved region is an $\sim 115$ amino acid maxi-KH RNA-bind- 
ing motif that differs from the canonical FMR1/Nova KH motif by containing three loops that are conserved among GSG/STAR proteins (Gibson et al. 1993; Musco et al. 1996; Lewis et al. 2000). Additionally, there are $~ 50$ amino acids and $\sim 25$ amino acid conserved regions that are $\mathrm{N}$-terminal and $\mathrm{C}$-terminal to the maxi-KH motif, respectively. The GSG/STAR domain is essential for in vivo function, as missense mutations in nine different conserved residues alter or eliminate gld-1 function (Francis et al. 1995a; Jones and Schedl 1995). GLD-1 is localized to the germ line cytoplasm, consistent with a role in regulating mRNA translation or stability (Jones et al. 1996).

GLD-1 is essential for oogenesis and meiotic prophase progression in C. elegans. The adult hermaphrodite germ line displays distal to proximal polarity in oocyte production (shown schematically in Fig. 1; see Schedl 1997). The distal-most germ cells (up to 20 cell diameters from the distal tip) are proliferative and serve as a stem cell population. Moving proximally, germ cells enter and progress through early stages of meiotic prophase (leptotene and zygotene) in the transition zone, which is then followed by an extended pachytene region. From the loop through the proximal region, nuclei progress from pachytene to diplotene and then diakinesis, while the oocytes become more fully cellularized, grow in size, and accumulate maternal products, such as yolk, to drive embryogenesis. The first $\sim 40$ germ cells that enter meiosis and undergo gametogenesis in each gonad form sperm in the fourth larval stage, whereas germ cells that subsequently enter meiosis form oocytes during adulthood. Null gld-1 alleles abolish oogenesis, causing female-specific defects in meiotic prophase progression-oogenesis (Francis et al. 1995a,b). Male germ line development, when it occurs, is normal. Mutant female germ cells enter and progress into pachytene, but then they exit the meiotic pathway and return to the mitotic cell cycle, forming a region of ectopic proliferation that is designated a germ line tumor. gld-1 null adult hermaphrodites accumulate oogenesis-specific transcripts in a pattern very similar to wild-type, confirming that female germ cells begin gametogenesis but are defective in progres- sion through meiotic prophase and oocyte differentiation (Jones et al. 1996). Partial loss-of-function gld-1 mutants show milder defects, including pachytene-arrested germ cells or the failure of oocytes to grow to the appropriate size.

In addition to its essential function in meiotic prophase progression-oogenesis, gld-1 has a redundant role in directing the initiation of meiotic development and/or inhibiting proliferation in premeiotic germ cells (Francis et al. 1995b; Kadyk and Kimble 1998). gld-1 also functions to promote male sex determination in the hermaphrodite germ line (Francis et al. 1995a,b). This is accomplished, at least in part, by GLD-1 binding to the 3'UTR of tra-2 mRNA and repressing its translation to permit spermatogenesis (Jan et al. 1999). GLD-1 binds FOG-2, a protein also required for male sex determination in the hermaphrodite germ line, forming a ternary complex with the tra-2 3'UTR that is likely responsible for translational repression (Schedl and Kimble 1988; Clifford et al. 2000). These GLD-1 functions, and the various gld-1 mutant phenotypes, suggest that GLD-1 has multiple RNA targets.

The distribution of GLD-1 in the germ line is nonhomogenous, which is likely important for its function. In the wild-type adult hermaphrodite germ line, the amount of GLD-1 is low at the distal end and increases to a maximum level in the transition zone where germ cells enter meiotic prophase (Figs. 1, 3; see Jones et al. 1996). The level of GLD-1 remains high in the cytoplasm of pachytene-stage germ cells. This expression pattern is consistent with the essential function of GLD-1 in female meiotic prophase progression and oocyte differentiation. In the loop region, as germ cells enter diplotene and begin oocyte growth, the level of GLD-1 decreases very sharply to undetectable levels, apparently as a result of protein instability and translational repression of new synthesis.

The nonhomogenous distribution of GLD-1, its role as a cytoplasmic RNA-binding protein and its female germ line-specific tumorous phenotype, leads to a model for the essential function of GLD-1 in female meiotic prophase progression-oocyte differentiation and the origin

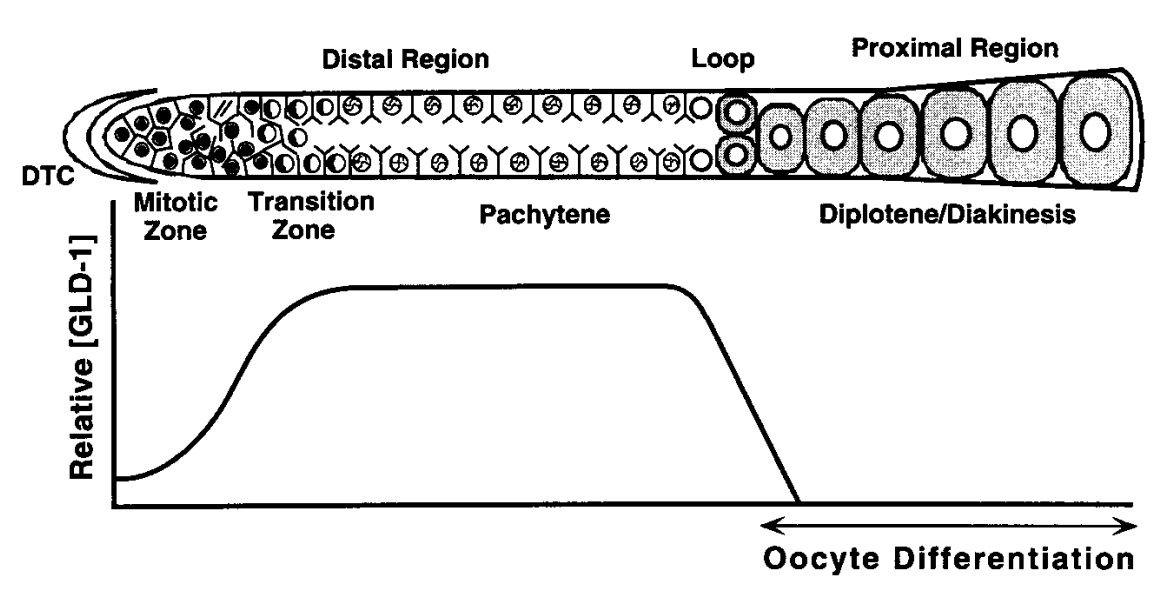

Figure 1. Schematic representation of the adult hermaphrodite germ line and qualitative depiction of GLD-1 protein levels. Diagram of a single wild-type adult hermaphrodite gonad arm (upper panel) is drawn linearly instead of its normal reflexed shape for comparison purposes. Our qualitative assessment of GLD-1 protein levels (y-axis) in the corresponding regions of the germ line ( $x$-axis) is shown in the lower panel. The gonad contains $\sim 1000$ germ nuclei. In the distal region, nuclei are arranged primarily around the periphery of the gonadal tube. Each nucleus is partially enclosed by plasma membranes; although this is a syncytium, each nucleus and its surrounding cytoplasm and membranes is called a germ cell. See text for details. 
of the tumorous phenotype (Francis et al. 1995a; Jones and Schedl 1995; Jones et al. 1996). The female germ line produces many maternal mRNAs during leptotene, zygotene, and pachytene that are translationally repressed. These maternal mRNAs are subsequently translated so that the protein products can be used in late-stage oocytes, meiotic maturation, meiotic divisions, and embryogenesis. GLD-1 was proposed to spatially restrict the translation of a subset of these maternal mRNAs; GLD-1 would translationally repress mRNAs during early meiotic prophase (leptotene to pachytene), and the elimination of GLD-1 as growing oocytes enter diplotene would allow these mRNAs to be translated. The tumorous phenotype, arising from germ cells leaving meiosis at the pachytene stage, is then proposed to be a result of premature translation during early meiotic prophase of $\mathrm{mR}$ NAs that would normally be repressed at this time. The inappropriate activity of certain prematurely translated proteins would in some way be incompatible with early meiotic prophase, causing germ cells to leave pachytene and begin proliferation. To test this model, it is necessary to isolate multiple mRNA targets of GLD-1, thereby identifying mRNAs with translation that is spatially regulated by GLD-1 and with premature translation that might lead to the tumorous germ line phenotype.

\section{Results}

Isolation of in vivo mRNA targets of GLD-1 using a novel biochemical approach

The scheme for a biochemical identification of in vivo mRNA targets of GLD-1 is shown in Figure 2A and is based on the premise that immunoprecipitation (IP) of GLD-1 from cytosol extracts should coprecipitate mRNAs that are bound by GLD-1. Functional GLD-1 for IP was obtained from a transgenic strain in which the gld1(q485) null mutant was rescued by an extrachromosomal array (ozEx40) containing wild-type GLD-1 with the FLAG epitope placed at the C terminus (GLD-1/ FLAG), distant from the RNA-binding domain. Western blot analysis with anti-GLD-1 antibody (Fig. 2B, top) shows a GLD-1/FLAG doublet from ozEx40 hermaphrodites, which migrates slightly slower than the wild-type GLD-1 doublet and is detected by the anti-FLAG antibody (Fig. 2B, middle). Staining of dissected adult hermaphrodite gonads from gld-1 null animals rescued by ozEx40 with either anti-GLD-1 or anti-FLAG antibodies shows the same spatial distribution of GLD-1/FLAG as that observed for GLD-1 in wild type (data not shown). These results indicate that GLD-1/FLAG is expressed at the appropriate time and place and in sufficient amounts so that target mRNAs are correctly regulated for rescue of the gld-1 null mutant.

Western blot analysis with anti-GLD-1 shows that GLD-1/FLAG can be specifically immunoprecipitated from cytosol extracts of ozEx40 adult hermaphrodites using anti-FLAG and eluted with FLAG peptide (Fig. 2C). RNAs that were coimmunoprecipitated and coeluted in FLAG IP and IgG IP were extracted, converted to cDNA
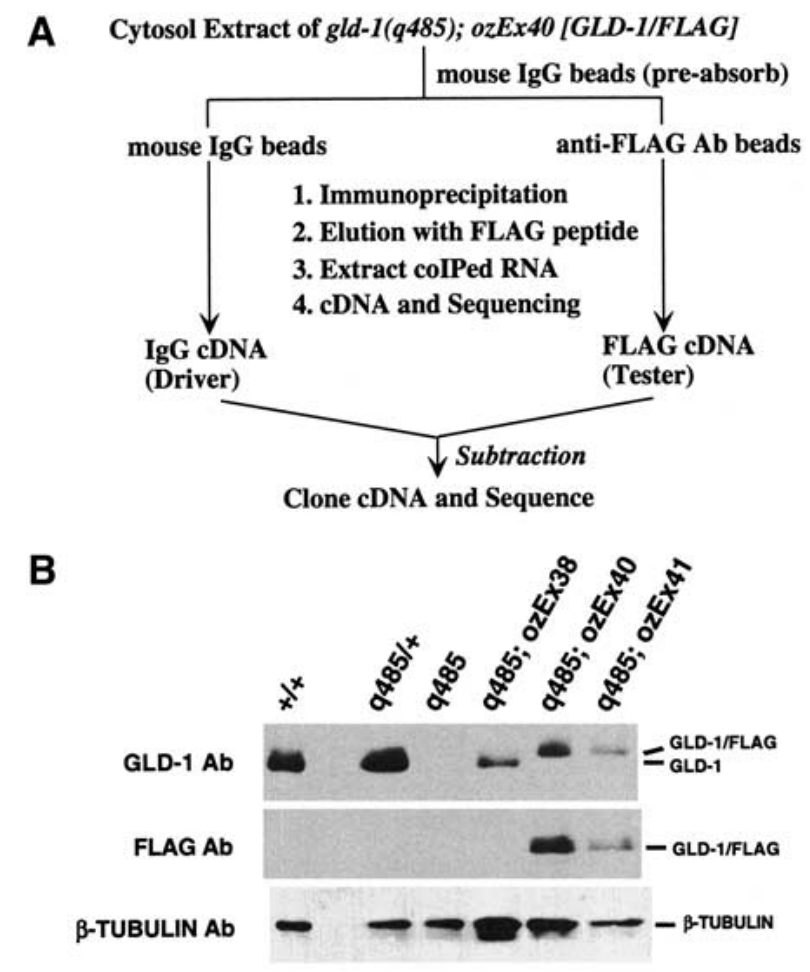

C

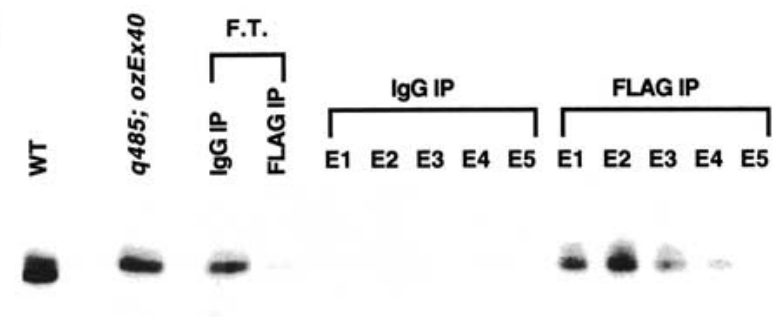

Figure 2. (A) Procedure for identification of mRNA targets of GLD-1. (B) GLD-1/FLAG expression from animals rescued by complex arrays. Western blot of total extracts from wild type $(+/+)$, gld-1 null heterozygote (q485/+), gld-1 null homozygote (q485), gld-1 null homozygote rescued with an untagged gld-1 genomic clone (q485;ozEx38), and gld-1 homozygote rescued with a FLAG-tagged gld-1 genomic clone (q485;ozEx40 and $q 485$;ozEx41) probed with anti-GLD-1 (top panel), anti-FLAG (middle panel), or anti- $\beta$-tubulin antibodies (n357, Amersham) as a loading control. Each lane contains 100 adult hermaphrodites of the given genotype. In rescued lines, adult hermaphrodites that have at least one rescued gonad arm were picked. $(C)$ Specific immunoprecipitation and elution of GLD-1/FLAG from the cytosol extract. Western blot of eluted proteins with FLAG peptide (E1-E5) after immunoprecipitation with nonimmune total mouse IgG (IgG IP) or with anti-FLAG antibody (FLAG IP) from the cytosol extract of q485; ozEx40 adult hermaphrodites. Flow through (F.T.) is the material that remained unbound after IgG IP or FLAG IP. The blot was probed with anti-GLD-1. Cytosol extract from wild-type adult hermaphrodites (WT) was loaded to show the untagged, endogenous GLD-1.

(FLAG cDNA and IgG cDNA), and cloned. Restriction enzyme mapping and sequencing of $\sim 300$ clones from both the FLAG IP and the IgG IP showed that $>70 \%$ of 
the cDNAs corresponded to mitochondrial RNA, ribosomal RNA, or ribosomal protein RNA (M.-H. Lee and T. Schedl, unpubl.), suggesting that these abundant RNAs were nonspecifically trapped during IP. Therefore, subtractive hybridization, using the IgG cDNA as a driver, was used to eliminate abundant RNAs that were trapped in the FLAG IP (Fig. 2A). Two independent subtractions were performed; the remaining cDNA populations were separately amplified by suppression PCR (Diatchenko et al. 1999|, cloned, and sequenced. From one subtraction, 211 clones were sequenced, corresponding to 94 different genes; from the other subtraction, 198 clones were sequenced yielding 89 genes (M.-H. Lee and T. Schedl, unpubl.). Seventeen genes were identified in both subtractions $(\sim 8 \times$ on average), and 15 were subjected to further analysis (Table 1).

To verify that identified mRNA species were specifically enriched in the FLAG IP, reverse transcription (RT)-PCR analysis was performed using gene specific primers on wild-type total RNA, IgG IP RNA, and FLAG IP RNA prepared from an independent cytosol extract. Fourteen mRNAs found in both subtractions were specifically enriched in the FLAG IP (Table 1), whereas cyp-3 mRNA (Y75B12B.5; M.-H. Lee and T. Schedl, unpubl.) and mitochondrial RNA were present in both IgG and FLAG IP, indicating that they were nonspecifically trapped during the IP. We next describe initial characterization of these 14 mRNAs and show from in-depth studies that one target, the yolk receptor mRNA, is a bona fide target that is bound and translationally repressed by GLD-1. We assume that the remaining 13 mRNA species are targets of GLD-1, although confirmation will require additional experiments.

\section{GLD-1 mRNA targets are expressed and can function} in the germ line

RNA targets of GLD-1 must be expressed in the germ line to be regulated by GLD-1 and may have important functions in germ line development or maternally directed embryonic development. To examine expression in the germ line, RT-PCR analysis was performed, comparing total RNA from wild type and from $g l p-1$ null adult hermaphrodites, which have essentially no germ line (Austin and Kimble 1987), using target specific primers. Eleven of the target mRNAs tested were only amplified from wild-type total RNA (Table 1, germ line specific), whereas three were preferentially amplified from wild type with some amplification from $g 1 p-1$ null total RNA (Table 1, germ line enriched).

Genes encoding GLD-1 target mRNAs can have important functions in germ line development and/or in early embryogenesis (Table 1). Mutation of the rme-2 yolk receptor causes partial sterility (Grant and Hirsh 1999), and mutation of lin-45 RAF causes arrest of germ cells in pachytene (M.-H. Lee, E. Lambie, and T. Schedl, unpubl.) similar to that observed for mpk-1 MAP kinase and mek-2 MAP kinase kinase (Church et al. 1995). RNA-mediated interference (RNAi; Fire et al. 1998) leads to defective oocytes for one target (B0244.8) and early embryonic lethality for each of two other targets (T05G5.7 and T23G11.2).

GLD-1 mRNA targets can define subsets of a gene family with redundant functions. Two genes of a six member chitin-binding domain family (cej-1 and B0280.5) were identified. RNAi of each gene alone has no phenotype, whereas RNAi of both cej-1 and B0280.5 causes embryonic lethality (Table 1). Three highly related puf genes (puf-6/-7/-10) of a ten member pumilio family (Zhang et al. 1997) were identified in both subtractions. A fourth, puf-5, was identified in only one subtraction. RT-PCR analysis confirmed that puf-5 is preferentially enriched in the FLAG IP (Table 1). RNAi of puf-6/-7/-10 or puf-5 has no phenotype, whereas RNAi for all four gives a late oogenesis defective phenotype. In contrast, puf family members $f b f-1$ and $f b f-2$ are expressed in the germ line but have a distinct phenotype from puf-6/-7/-10 and puf-5 RNAi (Zhang et al. 1977) and were not enriched in the GLD-1 FLAG IP when genespecific primers were tested (M.-H. Lee and T. Schedl, unpubl.).

\section{GLD-1 is a translational repressor of rme-2 $m R N A$}

To understand how GLD-1 regulates its targets, the expression pattern of each mRNA and its corresponding proteins must be evaluated both in wild-type and gld-1 null germ lines. The most extensively characterized of the targets is rme-2, which encodes the yolk receptor required for yolk uptake by late-stage oocytes (Grant and Hirsh 1999). We first compared the distribution of GLD-1 and RME-2 by antibody staining of dissected wild-type adult hermaphrodite gonads. GLD-1 and RME-2 accumulate in a reciprocal pattern in wild-type germ lines: RME-2 is absent from early meiotic prophase germ cells distal to the loop where GLD-1 is abundant in the cytoplasm; RME-2 increases in abundance in growing oocytes proximal to the loop where GLD-1 levels decrease precipitously and become undetectable (Fig. 3B; see Jones et al. 1996; Grant and Hirsh 1999). This mutually exclusive expression pattern suggests that GLD-1 inhibits RME-2 accumulation in the distal region. Consistent with GLD-1 acting as a negative regulator, RME-2 accumulates prematurely in plasma membranes of early meiotic prophase germ cells in the distal region of gld-1 null adult hermaphrodite germ lines (Fig. 3D). These results suggest models that include GLD-1 binding to rme-2 mRNA and either repressing its translation or causing its degradation. In either case, RME-2 level would be very low in the distal region of wildtype adult hermaphrodite germ lines and misexpressed in the distal region of gld-1 null adult hermaphrodite germ lines.

To distinguish between these two possibilities, RNA in situ analysis of rme-2 was performed in wild-type and gld-1 null hermaphrodite germ lines (Fig. 4). In wild-type adult hermaphrodites, rme-2 mRNA first appears at the end of the transition zone and increases to a high level by the end of pachytene; regions where GLD-1 protein is abundant but RME-2 protein is absent. Furthermore, 
Table 1. Characterization of $m R N A$ targets of $G L D-1$

\begin{tabular}{|c|c|c|c|c|c|c|}
\hline mRNA Targets ${ }^{\mathrm{a}}$ & $\begin{array}{l}\text { Total } \\
\text { RNA } \\
\end{array}$ & $\begin{array}{r}\text { IgG } \\
\text { RNA } \\
\end{array}$ & $\begin{array}{c}\text { FLAG }^{\mathrm{b}} \\
\text { RNA } \\
\end{array}$ & Homology & Germ line Expression $^{\mathrm{c}}$ & RNAi or mutant phenotype \\
\hline $\begin{array}{l}\text { Mito. RNA } \\
n c c-1 \text { (T05G5.3) }\end{array}$ & - & - & - & Cdc2 kinase & & \\
\hline T05G5.7 & $\Rightarrow$ & -3 & $\infty$ & human \& mouse EST & germ line enriched & embryonic lethal \\
\hline$c e j-1(\mathrm{C} 07 \mathrm{G} 2.1)$ & - & & 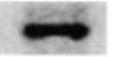 & chitin-binding domain & germ line specific & \\
\hline B0280.5 & $\Leftrightarrow$ & & & chitin-binding domain & germ line specific & \\
\hline F26D10.10 & 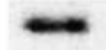 & & & glutamine synthetase & germ line specific & none \\
\hline H02I12.5 & $\infty$ & & & novel & germ line specific & none \\
\hline $\operatorname{lin}-45$ (Y73B6A.5) & -2 & & $\infty$ & Raf kinase & germ line enriched & pachytene arrest \\
\hline R09B3.1 & wise & & & AP endonuclease & germ line specific & none \\
\hline rme-2 (T11F8.3) & 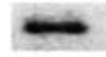 & & - & yolk receptor & germ line specific & partial sterile \\
\hline B0244.8 & $\infty$ & & 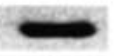 & LDL receptor & germ line specific & ovulation/fertilization def. ${ }^{\mathrm{g}}$ \\
\hline $\mathrm{T} 23 \mathrm{G} 11.2$ & $\cdots$ & & $\infty$ & acetyltransferase & germ line enriched & early embryonic lethal ${ }^{\mathrm{f}}$ \\
\hline Y75B12B.1 & - & & & novel & germ line specific & none \\
\hline puf-5 (F54C9.8) & - & & $\longrightarrow$ & pumilio & germ line specific & Jgametogenesis $^{\mathrm{h}}$ \\
\hline puf-6/-7/-10 & - & & $=$ & pumilio & germ line specific & \\
\hline
\end{tabular}

a For gene names/physical map positions of mRNA targets, see http://www.wormbase.org. Mitochondrial RNA is an example of an RNA that is nonspecifically trapped in the IP. ncc-1 mRNA is an example of an mRNA that is apparently not a target of GLD-1 binding. сур-3 (data not shown) was found in the two independent subtractions, but when tested by RT-PCR was found at equivalent levels in IgG IP RNA and FLAG IP RNA.

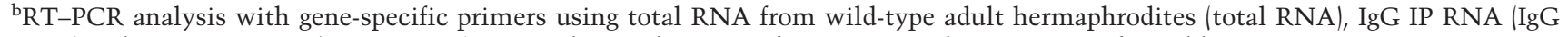
RNA) and FLAG IP RNA (FLAG RNA) as templates. Identities of RT-PCR products were confirmed by sequencing.

${ }^{\mathrm{c}}$ Germ line-expression was tested using RT-PCR of total RNA from wild-type adult hermaphrodites and compared to that of total RNA from $g 1 p-1$ (q175) adult hermaprodites. Absence of an RT-PCR fragment from $g l p-1(q 175)$ mutants indicates an adult hermaprodite germ-line specific mRNA. In cases where mRNA species were analyzed by Reinke et al. (2000), the results are identical.

${ }^{\mathrm{d}}$ The mutant phenotypes were characterized in lin-45(dx19) or as reported for rme-2 (Grant and Hirsh 2000). For the others, we examined the RNAi depletion phenotype by injecting dsRNA made from the corresponding cDNA at $1 \mathrm{mg} / \mathrm{mL}$ into wild-type young adult hermaprodites $(\mathrm{Po})$ followed by scoring the Po animals 48 to $72 \mathrm{~h}$ later and scoring the entire set of $\mathrm{F}_{1}$ progeny. In cases where RNAi analysis of the mRNA species was examined by Gonczy et al. (2000), Fraser et al. (2000), or Maeda et al. (2001), our results are similar.

'RT-PCR products from FLAG IP RNA were cloned and sequenced. Based on gene specific 3' sequences corresponding to puf-6 (F18A11.1), puf-7 (B0273.2), and puf-10 (Y48G1BL.E), all three pufs were identified. This indicates that all three pufs are expressed and are likely targets of GLD-1 regulation. These three pufs are considered as a group as they are $>97 \%$ identical at the nucleotide level, and thus RNAi of any one would deplete the others.

${ }^{\mathrm{f}} \mathrm{F}_{1}$ embryos have multiple nuclei without plasma membranes, as judged by Nomarski microscopy, suggesting a defect in cytokinesis. The embryos may also have weak egg shells. Single RNAi for C07G2.1 or B0280.5 gave no phenotype. Phylogenetic analysis indicates that these two chitin-binding domain containing proteins are closely related; a third predicted gene, R02F2.4, is more closely related to B0280.5 but it may not be expressed as there are no corresponding ESTs.

'Delayed and irregular ovulations were observed by time-lapse video Nomarski. Ovulated oocytes were not fertilized. This B0244.8 RNAi phenotype was observed at $25^{\circ} \mathrm{C}$ but not $20^{\circ} \mathrm{C}$.

${ }^{\text {h}}$ Single RNAi, for puf-5 or using a sequence that is identical in puf-6/-7/-10, gave no phenotype. RNAi against all four pufs gave a Po phenotype of a double row of small oocytes that are in diakinesis and an $\mathrm{F}_{1}$ phenotype of sterile hermaphrodites, which appear normal in the soma, but where the germ line contains reduced or no germ cells. Phylogenetic analysis indicates that PUF- 5 is the PUF protein that is most closely related to PUF-6/-7/-10, consistent with the products being functionally redundant.

even though rme-2 mRNA is already present in oogenic early meiotic prophase germ cells of wild-type late L4 hermaphrodites, where GLD-1 protein is abundant in the cytoplasm, RME-2 protein fails to accumulate (data not shown). Thus, GLD-1 appears to repress translation rather than destabilize rme-2 mRNA. rme-2 mRNA accumulates in a similar pattern in gld-1 null adult hermaphrodite germ lines, indicating that the increase in RME-2 protein accumulation in the distal region of gld-1 null is not the result of increased rme-2 mRNA stability. 

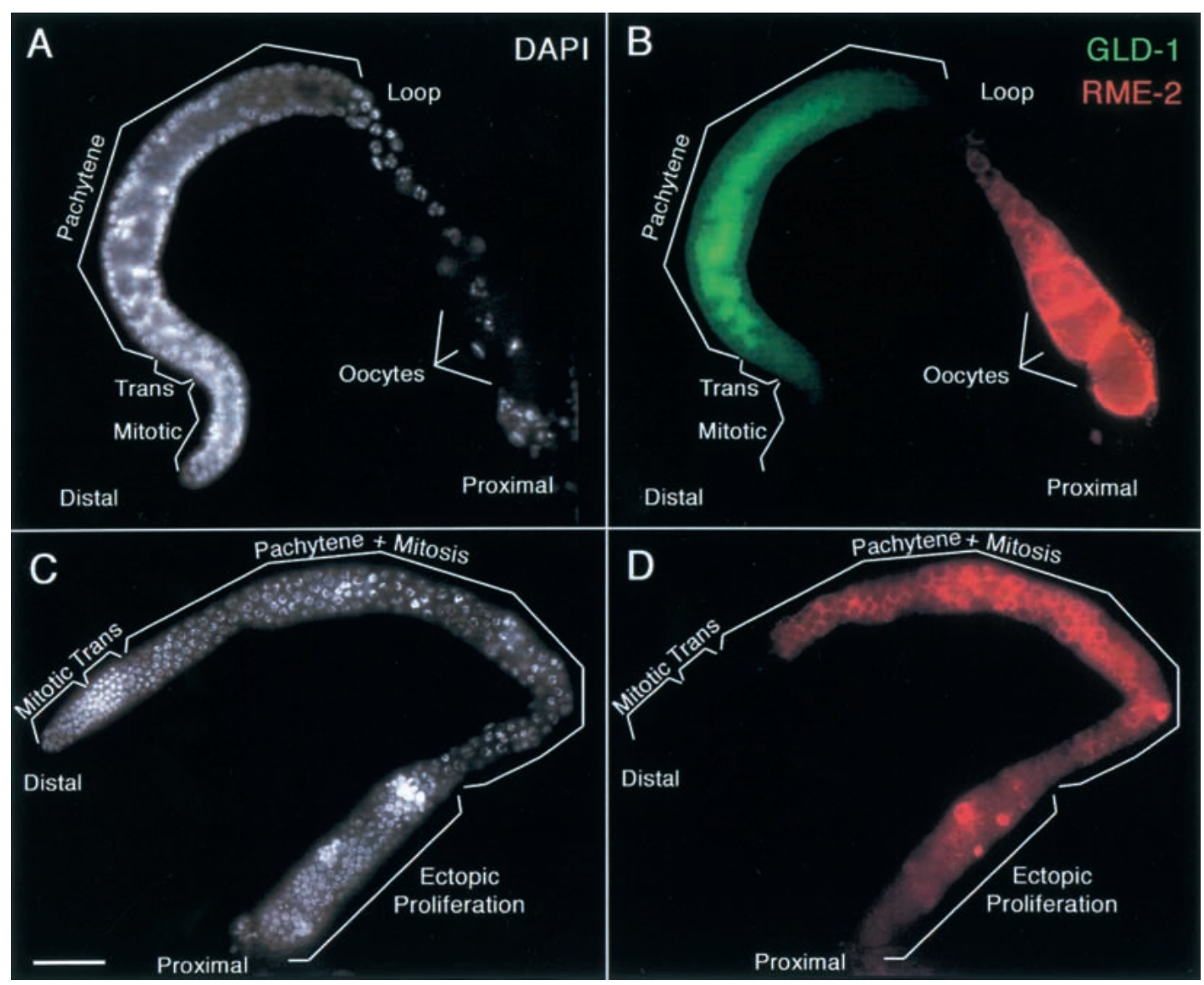

Figure 3. RME-2 yolk receptor accumulation is regulated by GLD-1. Gonad arms, dissected from a wild-type adult hermaphrodite $(A, B)$ or from a gld-1 null adult hermaphrodite $(C, D)$, stained with DAPI to visualize DNA $(A, C$ as white), rat anti-GLD-1 $(B$ as green), and rabbit anti-RME-2 (B,D as red). (B) GLD-1 and RME-2 accumulation is mutually exclusive. Composite shows an interior focal plane of an intact gonad. GLD-1 staining is the strongest in the transition zone and pachytene region. At the loop, as GLD-1 staining diminishes rapidly, RME-2 staining starts to appear. RME-2 staining becomes stronger and localized at the plasma membrane, as proximal oocytes become more fully cellularized and increase in volume. $(D)$ RME- 2 is misexpressed and localized at the plasma membrane of pachytene-stage germ cells in the distal region of the gld-1 null adult hermaphrodite germ line. At the proximal end, as germ cells proliferate ectopically, RME-2 staining is variable. Bar, $20 \mu \mathrm{m}$.

Taken together, the above results indicate that GLD-1 binds (see below) and represses the translation of rme-2 mRNA in the distal region of wild-type adult hermaphrodite germ lines. GLD-1 therefore functions to spatially restrict yolk uptake to the most proximal oocytes by translational repression of the rme-2 mRNA.

\section{Target-specific function for a protein cofactor} of GLD-1-mediated repression

FOG-2 acts as a cofactor with GLD-1 in the translational repression of the tra-2 mRNA (Clifford et al. 2000). To test whether FOG-2 also functions as a cofactor in the translational repression of $r m e-2$ mRNA, we stained fog-2 null mutant females with anti-RME-2 antibodies. RME- 2 accumulation in fog- 2 mutants was identical to that of wild-type hermaphrodites (data not shown), indicating that FOG-2 does not have an essential function in the translational repression of $r m e-2$ mRNA.
GLD-1 binds to sequences at the 5' and $3^{\prime}$ ends of rme-2 mRNA

To begin to understand how GLD-1 represses rme-2 translation, it is important to identify the site(s) within the 2896-nt mRNA (Grant and Hirsh 1999) to which GLD-1 binds. We used the biotin-RNA pull-down assay of Nabel-Rosen et al. (1999) to identify GLD-1-binding regions. Four RNA fragments corresponding to the entire rme-2 mRNA (Probes 1 through 4; Fig. 5A,B) were biotinlabeled, separately incubated with cytosol extracts from wild-type adult hermaphrodites, and the RNA-protein complexes were isolated with streptavidin-magnetic beads. The presence of GLD-1 within the RNA-protein complex was determined by Western blotting. GLD-1 was previously shown to bind the wild-type tra-2 3'UTR but not the 3'UTR of gain-of-function mutant tra2(e2020) that has an internal deletion (Jan et al. 1999; Clifford et al. 2000). The biotin-RNA pull-down assay behaves similarly to the previously used gel shift and 
Figure 4. Accumulation of rme-2 mRNA in wild-type and gld-1 null adult hermaphrodite germ lines. A dissected wild-type adult hermaphrodite gonad (upper panel) showing rme-2 mRNA (purple staining) is first detected in early meiotic prophase, in the transition zone, and progressively increases to a high level in late-stage oocytes. A dissected gld-1 null adult hermaphrodite gonad (lower panel) showing rme-2 mRNA is first detected in early meiotic prophase and then increases to a higher level in pachytene that is maintained through the proximal tumorous region. The level of rme-2 RNA appears lower in gld-1 null than wild-type hermaphrodites, possibly because GLD-1 partially stabilizes the mRNA or transcription of $r m e-2$ is reduced in tumorous germ cells. Bar, $20 \mu \mathrm{m}$.

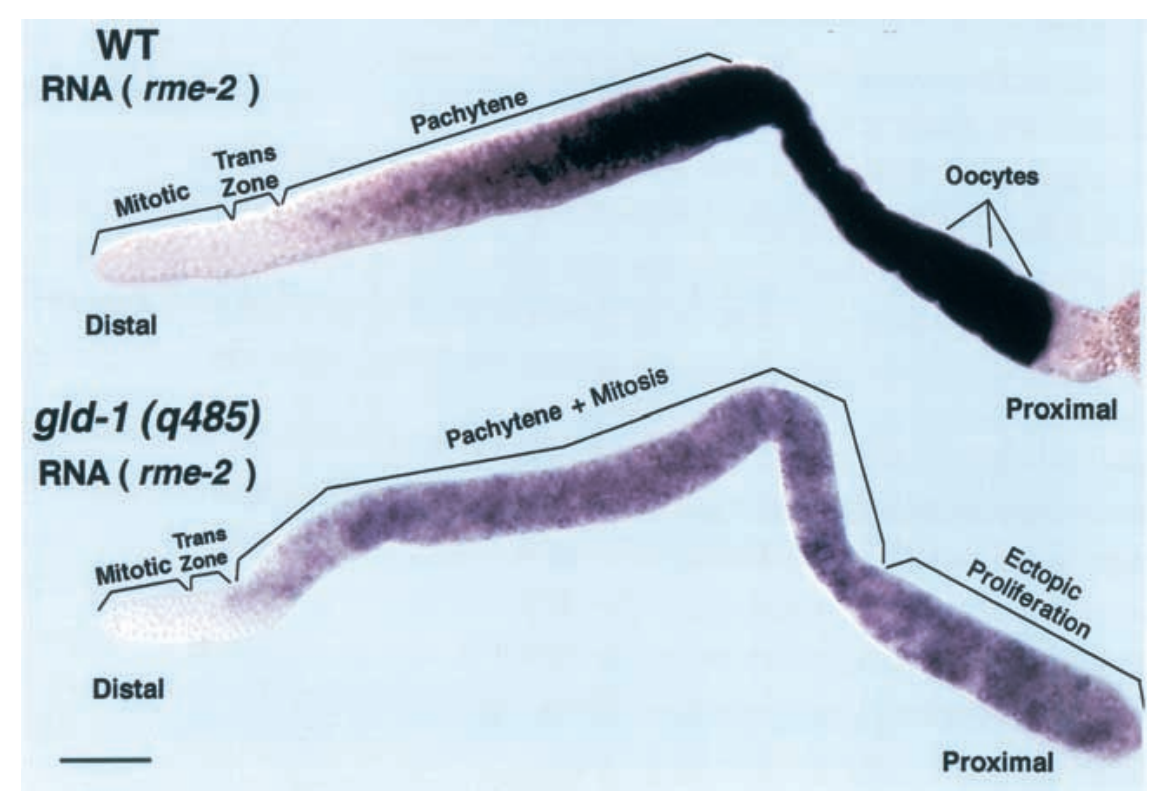

ultraviolet (UV)-cross-link assays, as GLD-1 from cytosol extract associates with wild-type tra-2 3'UTR but not with tra-2(e2020) 3'UTR (Fig. 5B). For rme-2, GLD-1 associates only with Probe 1 , which has both the $5^{\prime}(1-248)$ and the 3' (2480-2896) ends of the rme-2 mRNA (Fig. 5B). Using a series of biotin-labeled RNAs within Probe 1 (Probes 5 through 11), we found that a $50 \mathrm{nt}$ RNA (Probe 9) in $5^{\prime}$ coding sequences and an 84 nt $3^{\prime}$ UTR RNA (Probe 11) were each sufficient for GLD-1 to bind (Fig. $5 \mathrm{C}, \mathrm{D})$. This suggests that there is at least one GLD-1binding site in the $5^{\prime}$ end (Probe 9) and at least one in the 3'UTR (Probe 11) of rme-2 mRNA. Alignment of Probe 9 and Probe 11 revealed CTT/ATTTATT in common. Probe 11 also has a similar second sequence, CTATTTTTG. Substitution of GGG for TTT /CTTGG GATT; Probe 9M1) severely reduced association with GLD-1 (Fig. 5C,D). A corresponding substitution of GGG for TTT (CTAGGGATT; Probe 11M2) greatly reduced association with GLD-1, whereas the substitution into the second site (Probe 11M1, CTAGGGTTG) had at best only a minor effect. When both mutations were introduced (Probe 11M3), the association with GLD-1 was very similar to that of Probe $11 \mathrm{M} 2$ (Fig. 5C,D). These data suggest that TTT within the sequence (CTT/ATT TATT) may be part of GLD-1-binding sites in rme-2 mRNA.

GLD-1 in cytoplasmic extracts may directly bind rme-2 RNA or may associate with the RNA indirectly via another protein. To distinguish between these possibilities, ${ }^{32} \mathrm{P}$-labeled RNAs were incubated with cytosol extract from wild-type adult hermaphrodites, and the RNA was cross-linked to cellular proteins by UV treatment. Following RNase digestion to remove unprotected RNA, GLD-1 and any remaining label to which it bound was purified by anti-GLD-1 IP and SDS-PAGE. GLD-1 was specifically labeled with rme-2 mRNA (Probe 1) as well as with wild-type tra-2 3'UTR (Fig. 6), all of which showed specific association with GLD-1 in the biotin-
RNA pull-down assay (Fig. 5A-D). GLD-1 also crosslinked with Probes 9 and 11 (data not shown). The RNA cross-linking indicates that GLD-1 binds these RNAs directly at specific sites, although it does not rule out the possibility that another protein(s) assists or stabilizes the interaction.

\section{RNA targets can differ in their ability to be bound by mutant GLD-1}

The availability of multiple RNA targets allows examination of whether mutations in GLD-1 affect binding to different targets equivalently. As a first step, we have examined two mutant versions of GLD-1 for their binding to the $5^{\prime}$ and $3^{\prime}$ rme-2 sites and the tra-2 3'UTR. The gld-1(q361) G227D mutation affects the first G of the invariant GXXG sequence found in all $\mathrm{KH}$ motifs and displays the null tumorous phenotype (Francis et al. 1995a; Jones and Schedl 1995). GLD-1(q361) fails to bind the tra-2 3'UTR in vitro (Jan et al. 1999) and in worm cytoplasmic extracts (Clifford et al. 2000), and, when an equivalent mutation was engineered into SAM68, disrupts binding to poly(U) (Chen et al. 1997). Staining of gld-1(q361) mutants shows misaccumulation of RME-2 in the early meiotic prophase germ line similar to that of gld-1(q485) (Fig. 3D; M.-H. Lee and T. Schedl, unpubl.), indicating that GLD-1(q361) is not able to translationally repress rme-2 mRNA. It is thus not surprising that GLD-1(q361) is unable to bind rme-2 RNAs in the biotin-RNA pull-down assay (Fig. 7A).

The gld-1(q126) G308E mutation is within the GSG domain in a region $\mathrm{C}$-terminal to the maxi-KH motif, changing a residue that is conserved in quaking and how. gld-1(q126) disrupts the GLD-1 function, directing male sex determination in the hermaphrodite germ line without affecting function to direct meiotic prophase progression-oogenesis (Francis et al. 1995a; Jones and Schedl 1995). The defect is dose dependent, as animals trans- 


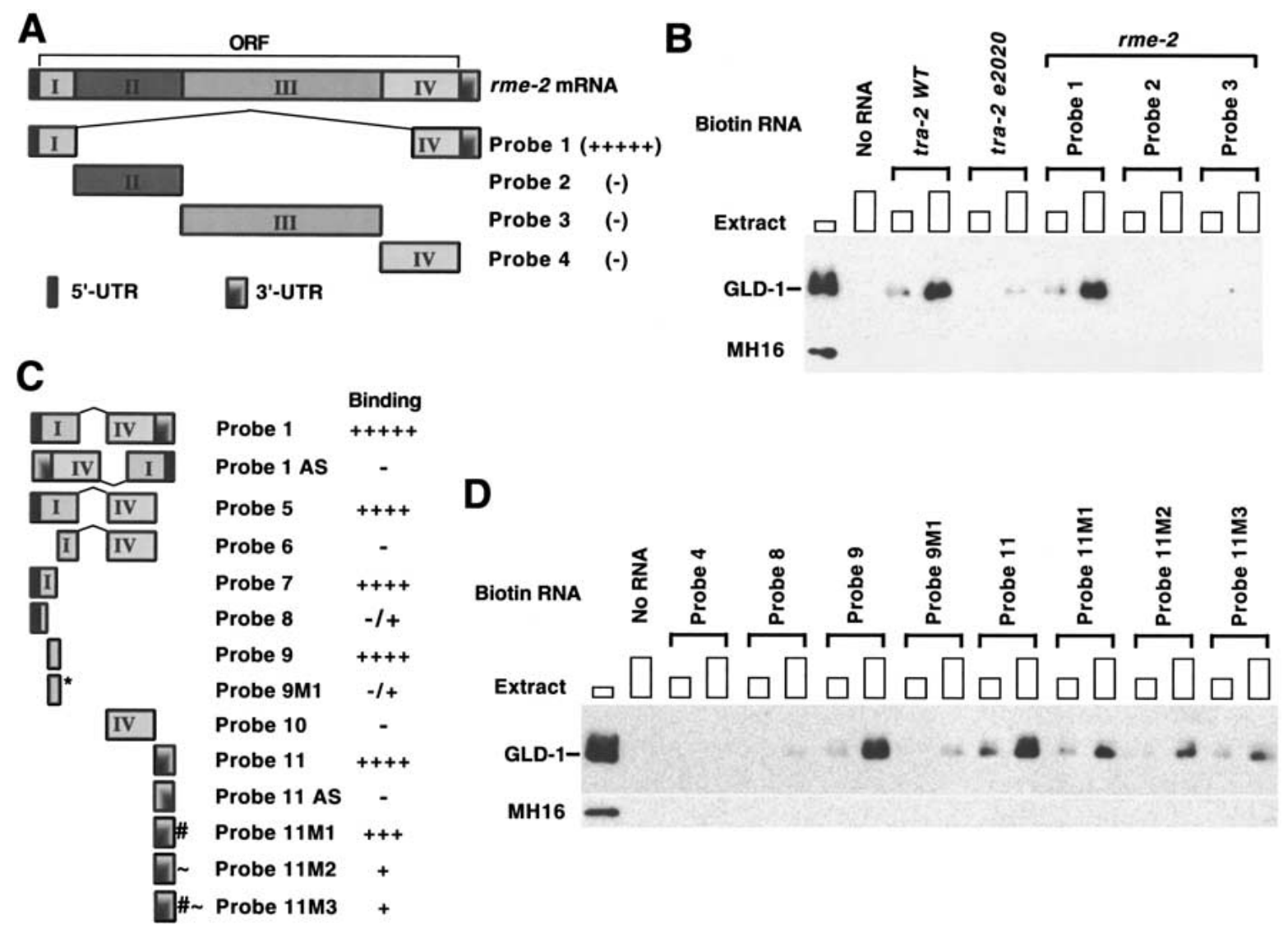

Figure 5. GLD-1 binds to sequences at both the $5^{\prime}$ and the $3^{\prime}$ ends of rme-2 mRNA. $(A, C)$ Schematic diagram of RNA probes. $(B, D)$ Each biotin-labeled RNA or control sample (No RNA) was allowed to form a complex with increasing amounts of cytosol extract ( 50 $\mu \mathrm{g}$ or $\sim 150 \mu \mathrm{g}$ of total protein) from wild-type adult hermaphrodites and the complex isolated with streptavidin magnetic beads. The isolated proteins were subjected to Western analysis with anti-GLD-1 antibody. The first lanes show total GLD-1 in cytosol extract $(\sim 30 \mu \mathrm{g})$. The tra-2 WT 3'UTR and the tra-2(e2020) mutant 3'UTR $(B)$ are control probe RNAs that should bind and not bind GLD-1, respectively. MH16 (anti-Paramyosin antibody) was used as a negative control. Probe 1 in $A$ and $C$ is identical; Probe 1 AS and Probe 11 AS are antisense versions. For the nucleotide positions of each rme-2 RNA fragment used as a probe for GLD-1 binding, see our web site: (http://www.genetics.wustl.edu/tslab/leesup.html).

heterozygous with gld-1 null (q126/q485) are 100\% feminized, whereas homozygous mutants (q126/q126) are $76 \%$ feminized. Because these females are fertile when mated, GLD-1(q126) is likely to bind and appropriately regulate most of its RNA targets. Consistent with this interpretation, RME-2 accumulates in gld1(q126/q485) females in a pattern that is indistinguishable from wild-type hermaphrodites (data not shown), and GLD-1 (q126) binds as efficiently as wild type to both the $5^{\prime}$ and $3^{\prime}$ rme-2 RNA sequences (Fig. 7B). However, the feminization phenotype suggests that GLD-1(q126) may be defective in binding a specific target involved in sex determination, such as tra-2 mRNA, and/or may be defective in binding a protein involved in sex determination. We found that the binding activity of GLD$1(q 126)$ to the wild-type 3'UTR of tra-2 is greatly impaired (Fig. 7B vs. wild-type GLD-1 in Fig. 5B). The above results indicate that GLD-1 G308E disrupts binding to one target, the tra-2 3'UTR, but does not affect binding to two other targets, the $5^{\prime}$ and $3^{\prime}$ sites in the rme-2 mRNA.

\section{Discussion}

Genetic studies suggest that GLD-1 acts on multiple RNA targets in its control of meiotic prophase progression/oogenesis, initiation of meiotic development, and germ line sex determination. We have used IP of endogenous protein-RNA complexes followed by subtractive hybridization and cloning to identify multiple in vivo targets of GLD-1. A diverse set of mRNAs, based on homology and mutant/RNAi phenotype (Table 1), were identified that have come under GLD-1 control. For one target, the rme-2 yolk receptor mRNA, we have shown that GLD-1 acts as a translational repressor (Figs. 3, 4) and binds directly to the RNA in worm cytoplasmic extracts (Fig. 6). Data presented here support the model that GLD-1 functions in oogenesis, at least in part, by acting as a translational repressor during early meiotic prophase of mRNAs that function in late oogenesis, meiotic maturation/meiotic divisions, and early embryogenesis. The identification of multiple mRNA targets will assist in our understanding of GLD-1 function in germ line development and provides an entrée for investiga- 


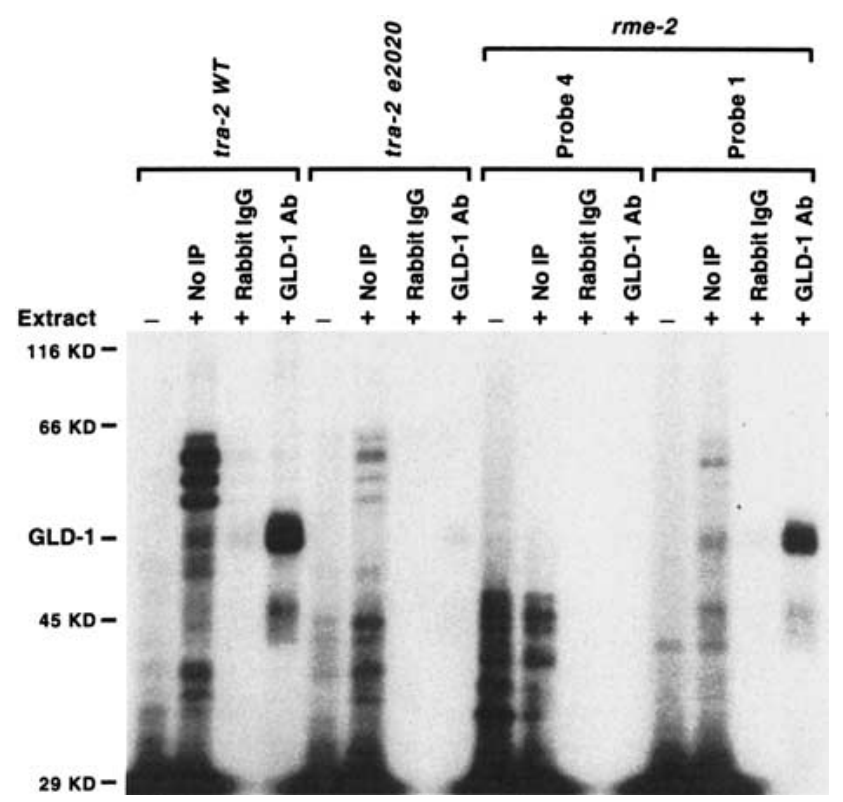

Figure 6. GLD-1 directly contacts rme-2 RNA. ${ }^{32} \mathrm{P}-$ labeled RNAs, tra-2 wild-type (WT) 3'UTR, tra-2(e2020) 3'UTR, or rme-2 Probe 4 or Probe 1 were incubated with (+) or without (-) cytosol extract ( $\sim 60 \mu \mathrm{g}$ of protein) from wild-type adult hermaphrodites, cross-linked with UV, digested with RNase A, and immunoprecipitated with rabbit IgG (Sigma) or with antiGLD-1 antibody (GLD-1 Ab). (No IP lanes) loaded with 10\% of total material used in the experiment; (Rabbit IgG and GLD-1 $\mathrm{Ab}$ lanes) loaded with $100 \%$ of material after immunoprecipitation. Molecular masses and GLD-1 are indicated. Similar results were obtained with Probe 9 or Probe 11 . We note that there are several polypeptides that bind the wild-type 3'UTR of tra-2 but are impaired in binding the 3'UTR of tra-2(e2020). They may represent RNA binding proteins that participate in translational repression through the 3'UTR or may regulate the reported localization of tra-2 mRNA (Graves et al. 1999).

tion of similarities and differences in regulation of distinct targets. The IP-subtractive hybridization method described here should be applicable to the identification of targets for other RNA-binding proteins; for example, identification of in vivo RNA targets of FMR1 would likely provide important insights into the etiology of fragile X-syndrome.

\section{GLD-1 acts as a translational repressor to spatially restrict yolk accumulation}

In the hermaphrodite, yolk proteins synthesized in the intestine (Kimble and Sharrock 1983) are taken up via the RME-2 yolk receptor into late-stage/full grown proximal oocytes (Grant and Hirsh 1999). GLD-1 acts as a translational repressor of rme-2 mRNA to spatially restrict RME-2 synthesis, and thus the accumulation of yolk, to late-stage oocytes. In gld-1 null hermaphrodites, the absence of GLD-1-mediated translational repression results in inappropriate RME-2 synthesis in the distal gonad (Fig. 3) and yolk accumulation in pachytene germ cells (data not shown). Spatial restriction of RME-2 accumulation allows yolk uptake to occur only in large oocytes, at positions where abundant pores in the somatic gonadal sheath provide the oocyte direct access to yolk particles in the pseudocoelomic space (Hall et al. 1999|. Spatial control of yolk receptor synthesis during oogenesis by GLD-1-mediated translational repression may be evolutionarily conserved as an identical mutually exclusive accumulation pattern is observed in the closely related nematode species C. briggsae and C. remanei for cross-reacting GLD-1 and RME-2 antigens (data not shown).

\section{GLD-1 regulates multiple targets}

Initial characterization of 14 additional mRNAs identified by the IP-subtractive hybridization method suggests that they are also targets of GLD-1 regulation (Table 1).
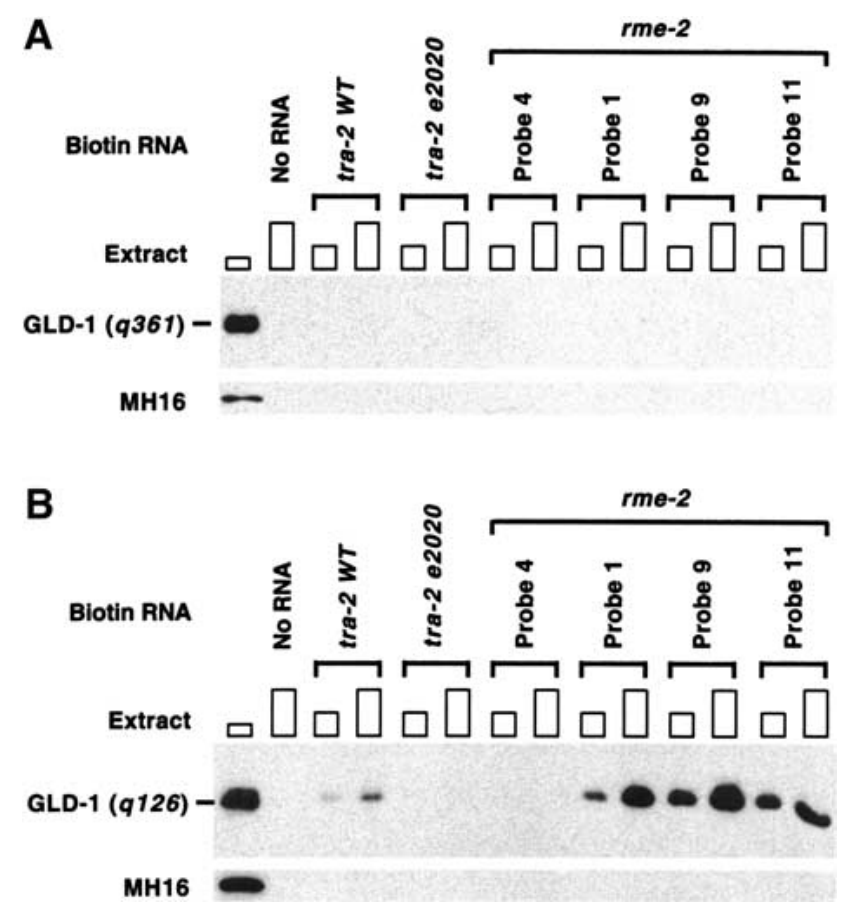

Figure 7. RNA-binding activity of GLD-1 mutants correlates with their translational repression activity in vivo and their phenotype. Each biotin-labeled RNA was allowed to form a complex with increasing amounts of cytosol extracts $(\sim 50 \mu \mathrm{g}$ or $\sim 150 \mu \mathrm{g}$ of proteins) from gld-1(q361); ozEx40 adult hermaphrodites $(A)$ or from females and males of q126/q485 trans-heterozygote $(B)$ and isolated with streptavidin magnetic beads. The isolated proteins were subjected to Western analysis with anti-GLD-1 antibody. The first lanes show total GLD-1(q361) $(A)$ or GLD-1 $(q 126)(B)$ in cytosol extract $(\sim 30 \mu \mathrm{g})$. Since gld1(q361); ozEx40 animals have GLD-1(q361) at normal levels but GLD-1/FLAG at less than one-twentieth of the normal level, GLD-1 found in $A$ is essentially all the GLD-1(q361). We estimate that GLD-1(q126) forms a complex with the tra-2 3'UTR at one-fifth to one-tenth of the efficiency as wild-type GLD-1. Decreased binding of GLD-1(q126) to the tra-2 3'UTR, and thus presumably increased TRA-2 accumulation, may in part account for the feminized hermaphrodite germ line phenotype of gld-1(q126). However, because gld-1(q126) mutants also show feminization of the tra-2 null male germ line, GLD-1(q126) must have an additional tra-2 independent defect (Francis et al. 1995b). 
Confirmation that these RNAs are targets and determination of their mode of regulation by GLD-1 will require analysis of protein and mRNA accumulation in wildtype and gld-1 null animals. GLD-1 likely regulates the translation and/or stability of RNA targets other than rme-2 and tra-2; preliminary results with two additional targets indicates that they are translationally repressed by GLD-1 in a manner similar to rme-2 (M.-H. Lee, R. Lin, and T. Schedl, unpubl.).

rme-2 and the other 14 mRNAs described here do not represent all of the RNA targets of GLD-1. We limited the analysis to RNAs that were identified in two parallel subtractive-hybridization/cloning experiments. Some mRNAs identified in only one of the subtractive-hybridization/cloning experiments are likely to be true targets (e.g., puf-5). However, some RNAs identified only in one experiment are probably not targets as they were not enriched in the FLAG IP when retested by PCR (M.-H. Lee and T. Schedl, unpubl.). Also, we failed to identify tra-2 mRNA with the IP-subtractive hybridization/cloning method, possibly because it is a rare message and/or because it is a low-affinity binder. Additional targets would likely be identified by replacing the inefficient cloning step with hybridization of the control IP and FLAG IP cDNA pools to microarrays containing a unigene set of cDNAs. Further, it is possible that the method of cytosol extract preparation and of IP may have resulted in loss of certain targets.

Members of a gene family that are functionally redundant are likely to have similar expression patterns. Such coordinate regulation can be accomplished by the genes coming under control of a common regulator or by distinct regulators acting in a similar manner. Remarkably, in the RNA targets identified, there are subsets of two gene families that are likely coregulated by GLD-1; two genes of a six member family that contains a chitinbinding domain, and four genes of a 10 member pumilio (puf) family (Table 1). RNAi studies indicate that the two proteins containing a chitin-binding domain function redundantly in early embryogenesis and that genes puf-5, puf-6, puf-7, and puf-10 function redundantly in late oogenesis. Thus, GLD-1 appears to coregulate functionally redundant subsets of the chitin binding domain gene family and the pumilio gene family.

Studies of rme-2 translational control support the model (see Introduction) that premature translation of certain RNA species during early meiotic prophase (lepotene through pachytene), which would normally not be translated until diplotene/diakinesis oocytes, may lead to the gld-1 null tumorous phenotype. Does misregulation of any of the currently identified targets (Table 1) contribute to gld-1 null tumor formation? Tumor formation is not suppressed in the gld-1 null rme-2 null double mutant or RNAi of Y75B12.1, R09B3.1, or H02I12.5 in gld-1 null (M.-H. Lee and T. Schedl, unpubl.), suggesting that misregulation of these mRNAs does not contribute to tumor formation. Interestingly, one of the targets is the lin-45 RAF kinase mRNA, which is a member of the RAS/MAP kinase cascade that functions in development and mammalian cell proliferation (Han et al. 1993;
Chang and Karin 2001). The gld-1 null tumorous phenotype is partly suppressed by loss of lin-45 function (M.-H. Lee, M. Ohmachi, and T. Schedl, unpubl.), suggesting that misregulation of the lin-45 RAF kinase mRNA contributes to tumor formation.

\section{What is the binding specificity of GLD-1?}

GLD- 1 binds to the $5^{\prime}$ coding and 3'UTR of rme-2 and the 3'UTR of tra-2 mRNAs, based on UV cross-linking and gel shift assays (this work; Jan et al. 1999; Clifford et al. 2000). It remains to be determined whether both sites in rme-2 are required in vivo for translational repression. Recent improvements in expression of transgenes in the germ line should facilitate the in vivo analysis (Praitis et al. 2001). The availability of more than one RNA target allowed testing whether mutant versions of GLD-1 bind to different targets equivalently in worm cytoplasmic extracts. GLD-1(q361), which contains a G227D mutation in the first $\mathrm{G}$ of the GXXG sequence found in all $\mathrm{KH}$ domains, fails to bind either rme-2 or tra-2 sites. In contrast, GLD-1(q126), which contains a G308E mutation within the GSG domain that is C-terminal to the maxi$\mathrm{KH}$ motif, is defective in binding only the tra-2 3'UTR. These results indicate that not only is the maxi-KH domain essential for RNA binding, but the surrounding homology region, which is unique to the GSG/STAR family, also contributes to binding. The defective binding of GLD-1(q126) to the tra-2 3'UTR but not to the rme-2 5' coding and 3'UTR can be explained in three ways. One possibility is that GLD-1 recognizes more than one binding site, with subregions of the GSG domain flanking the maxi-KH motif participating directly in RNA binding and providing specificity. Second, subregions of the GSG domain may be involved in proteinprotein interactions, which can differ from target to target, that affect RNA-binding specificity. Either or both of these mechanisms may provide an explanation for how GLD-1 can bind a diverse set of targets. Third, GLD-1 may bind to the tra-2 3'UTR with a lower affinity than the $5^{\prime}$ or $3^{\prime}$ sequences of rme-2, and the GLD-1(q126) mutant protein is partially defective in binding to all targets. In this scenario, the tra-2 3'UTR is preferentially affected because of its lower intrinsic binding affinity. This possibility is consistent with the observation that gld-1 null/+ has a weak haplo-insufficient feminization of the germ line (Francis et al. 1995a), presumably because translational repression of the tra-2 mRNA is inefficient when the level of GLD-1 is reduced by a factor of two. Note that the difference between tra-2 and rme-2 binding is likely to be FOG-2 independent as GLD1(q126) interacts normally with FOG-2 (Clifford et al. 2000).

Attempts to define a GLD-1 RNA-binding site computationally have thus far failed; a consensus sequence was not found among 3'UTRs of 14 targets when analyzed by programs BLAST, CONSENSUS, CLUSTAL, FOLDALIGN, Co-bind, and MEME/MAST (J. Gorodkin, E. Rivas, Z. Bao, S. Eddy and G. Stormo, pers. comm.). Possibly using shorter sequences from multiple targets 
where GLD-1-binding regions have been defined biochemically (e.g., Fig. 5) will assist the computational search.

\section{How does GLD-1 translationally regulate its target mRNAs?}

Initiation of translation is thought to involve the formation of a closed loop between the $5^{\prime}$ and $3^{\prime}$ ends of the mRNA (Sachs 2000). Because GLD-1 can bind both $5^{\prime}$ and $3^{\prime}$ ends of rme-2 mRNA and can also bind itself (Chen et al. 1997; B. Clifford and T. Schedl, unpubl.), a different inhibitory loop may be formed by GLD-1 binding to each end and then self-associating. Such an rme-2 mRNA loop-protein complex may inhibit the assembly of a translation initiation complex or prevent the translation machinery from progressing. Defining the GLD-1binding sites in other targets will determine if such a speculative model applies to other targets.

In a number of contexts (e.g., oocyte maturation in frogs), specific mRNAs gain poly(A) in the cytoplasm and become translationally active or lose poly(A) and become translationally inactive (Gray and Wickens 1998). The poly(A) tail length of several RNA targets, including rme-2 and tra-2, was assessed by the PCR-based poly(A) tail assay (Salles and Strickland 1995) using total RNA from wild type and gld-1 null, which lacks GLD-1-dependent translational repression. No significant difference in poly(A) tail length was observed between wild type and gld-1 null (M.-H. Lee and T. Schedl, unpubl.). This implies that GLD-1-mediated translational repression of at least some target mRNAs is by a mechanism that does not modulate poly(A) length (e.g., Olsen and Ambros 1999; Clark et al. 2000; Ostareck et al. 2001), although repression may interfere with other poly(A)dependent events (Thompson et al. 2000).

Relief of rme-2 translational repression occurs when GLD-1 levels drop dramatically in the transition of oocytes from pachytene to diakinesis. The decrease in GLD-1 levels is presumably a combination of degradation of GLD-1 and repression of translation (Jones et al. 1996). Relief of translational repression by degradation of a regulator has been shown previously for iron-response mRNAs, in which the regulator IRP2 is degraded as a consequence of increased iron levels (Rouault and Hartford 2000).

\section{Translational control of rme-2 and tra-2 occurs by distinct mechanisms}

Two lines of evidence suggest that translational control of rme-2 and tra-2 mRNAs are achieved by different GLD-1-dependent mechanisms. First, FOG-2 is a cofactor for GLD-1 in translational control of tra-2 (Clifford et al. 2000) but not rme-2 mRNA. Second, relief of rme-2 and tra-2 translational repression is achieved by distinct mechanisms. Although information on tempo$\mathrm{ral} / \mathrm{spatial}$ aspects of tra-2 translational control is not currently known, elimination of GLD-1 in diplotene/ diakinesis oocytes is not relevant as germ cell sexual fate must already have been specified (see also Clifford et al. 2000). A possible third line of evidence is that mutant GLD-1(q126) binds normally to rme-2 mRNA but is defective in binding tra-2 mRNA. However, we do not know if this is because the tra-2 3'UTR is a lower-affinity binding site or because there is a fundamental difference in the way that GLD-1 (and/or associated proteins) binds to sites in rme-2 and tra-2. The first two points, and studies by Sonoda and Warton (2001) with Drosophila pumilio, support the idea that different mRNA species, which are regulated by a particular transacting factor, can assemble mRNA-specific translational control complexes.

\section{Translational control during C. elegans oogenesis}

DNA microarray studies provide a catalog of transcripts that are restricted to oogenesis or spermatogenesis and those that are common to both (Reinke et al. 2000). However, because the germ line and the transition from oocyte to embryo rely heavily on posttranscriptional control mechanisms, transcript accumulation profiles provide only part of the picture of the temporal and spatial pattern of the germ line proteome. Our studies of GLD-1 mRNA targets can be incorporated with work of others to give an initial view of spatial control of the $C$. elegans oogenesis proteome. rme-2 and mex-3 mRNAs are present throughout meiotic prophase/oogenesis, but the proteins accumulate only in diplotene/diakinesis oocytes; translational repression of $r m e-2$ is controlled by GLD-1, whereas translational repression of mex-3 is GLD-1 independent (this work; Draper et al. 1996; Jones et al. 1996). Thus, there are at least two distinct mechanisms that give the same spatial accumulation patterntranslational repression during early meiotic prophase followed by relief of repression in growing oocytes in diplotene/diakinesis. Another set of mRNAs, exemplified by pal-1, skn-1, and apx-1, accumulate throughout oogenesis, but translation does not occur until embryogenesis, where it is blastomere specific (Bowerman et al. 1993; Hunter and Kenyon 1996; Mickey et al. 1996). For pal-1, translational repression during oogenesis is regulated, at least in part, by the MEX-3 KH domain-containing protein (Draper et al. 1996; Hunter and Kenyon 1996). A further set of mRNAs (e.g., glp-1 and gld-1) is present throughout the hermaphrodite germ line but show spatial protein accumulation patterns that likely reflect control of both translation and protein stability. For $g l p-1$, the mRNA is translated only in the distal proliferative region, with translational repression and protein destabilization during meiotic prophase (Crittenden et al. 1994). For gld-1, the mRNA is translated in proliferative and early meiotic prophase germ cells, with translational repression and protein destabilization occurring in diplotene/diakinesis oocytes (Jones et al. 1996). Future studies will provide a more comprehensive understanding of spatial control of protein accumulation during oogenesis. 


\section{Materials and methods}

\section{Nematode strains and culture}

Standard procedures for nematode culture and genetic manipulation were followed with growth at $20^{\circ} \mathrm{C}$ unless indicated (Sulston and Hodgkin 1988). Descriptions of C. elegans genes, alleles, and phenotypes relevant to this study are in Francis et al. (1995a) and Hodgkin and Martinelli (1999).

\section{Rescue of gld-1 mutants by GLD-1/FLAG transgenic arrays}

The FLAG epitope was inserted into the C terminus of GLD-1 within a 6.8-kb gld-1 genomic clone (pAJ37; Jones and Schedl 1995), forming GLD-1/FLAG, pMHL04. pAJ37 or pMHL04 was linearized with XhoI and injected into unc-13(e51) gld-1(q485) heterozygous animals at $0.25 \mathrm{ng} / \mu \mathrm{L}$ in a mix containing total N2 genomic DNA (ScaI digested, $98 \mathrm{ng} / \mathrm{\mu L}$ ), pRF4 [rol-6 (su1006)] (ScaI digested, $1 \mathrm{ng} / \mu \mathrm{L})$, and pJW1011 [cap-1::gfp] (EcoRI digested, $0.25 \mathrm{ng} / \mu \mathrm{L}$; Waddle et al. 1996) to form complex extrachromosomal arrays (Kelly et al. 1997). Rolling and GFPpositive $\mathrm{F}_{1}$ heterozygous animals were picked to identify lines with gld-1 rescuing activity. Crosses with $o z E x 40$ were used to generate unmarked gld-1 null (q485) or q361 strains. ozEx40 was chosen for use because it contained the highest proportion of rescued animals; 20\% of gld-1(q485); ozEx40 animals have one or both gonad arms rescued to produce viable progeny. We estimate that the level of GLD-1/FLAG in rescued gld-1(q485); ozEx40 hermaphrodites is approximately one fourth of that found in wild-type (Fig. 2). Therefore, animals used in biochemical experiments that are progeny of gld-1(mutant); ozEx 40 have GLD-1/FLAG at less than one twentieth of the level of GLD-1 in wild-type.

\section{Other methods}

Western blotting, antibody staining, and in situ hybridization to dissected gonads and UV cross-linking of GLD-1 to RNA are described in Jones et al. (1996) and Clifford et al. (2000). Rabbit anti-RME-2 antibodies were generously provided by Barth Grant and David Hirsh (Columbia University College of Physicians and Surgeons, New York, NY). Detailed protocols for cytosol extract preparation, immunoprecipitation, subtractive hybridization/cloning, RT-PCR analysis, biotin-RNA pull-down assay, and rme-2 cDNA constructs used in defining the regions of the mRNA that binds to GLD-1, as well as all results indicated in the text as data not shown, can be found at our Web site (http://www.genetics.wustl.edu/tslab/leesup.html).

\section{Acknowledgments}

We thank B. Grant and D. Hirsh for generously providing RME-2 antibody; Y. Kohara for cDNA clones; R. Lee for suggesting the subtraction/suppression PCR protocol; D. Hansen, M. Johnston, G. Seydoux, A. Fire, P. Kuwabara, B. Grant, S. Nayak, and the reviewers for helpful comments on the manuscript; J. Gorodkin, E. Rivas, Z. Bao, S. Eddy, and G. Stormo for the computational analysis of target mRNAs; and C. Hresko for providing MH16 antibody. This work was supported by $\mathrm{Na}$ tional Institutes of Health grant no. RO1 GM63310 to the Schedl laboratory.

The publication costs of this article were defrayed in part by payment of page charges. This article must therefore be hereby marked "advertisement" in accordance with 18 USC section 1734 solely to indicate this fact.

\section{References}

Austin, J. and Kimble, J. 1987. $g 1 p-1$ is required in the germ line for regulation of the decision between mitosis and meiosis in C. elegans. Cell 51: 589-599.

Bowerman, B., Draper, B., Mello, C., and Priess, J. 1993. The maternal gene $s k n-1$ encodes a protein that is distributed unequally in early C. elegans embryos. Cell 74: 443-452.

Chang, L. and Karin, M. 2001. Mammalian MAP kinase signalling cascades. Nature 410: 37-40.

Chen, T., Damaj, B., Herrerra, C., Lasko, P., and Richard, S. 1997. Self-association of the single-KH domain family members Sam68, GRP33, GLD-1 and Qk1: Role of the KH domain. Mol. Cell. Biol. 17: 5707-5718.

Church, D.L., Guan, K.L., and Lambie, E.J. 1995. Three genes of the MAP kinase cascade, mek-2, mpk-1/sur-1, and let-60 ras are required for meiotic cell cycle progression in Caenorhabditis elegans. Development 121: 2525-2535.

Clark, I.E., Wyckoff, D., and Gavis, E.R. 2000. Synthesis of the posterior determinant Nanos is spatially restricted by a novel cotranslational regulatory mechanism. Curr. Biol. 10: 1311-1314.

Clifford, R., Lee, M.H., Nayak, S., Ohmachi, M., Giorgini, F., and Schedl, T. 2000. FOG-2, a novel F-box containing protein, associates with the GLD-1 RNA binding protein and directs male sex determination in the C. elegans hermaphrodite germline. Development 127: 5265-5276.

Crittenden, S., Troemel, E., Evans, T., and Kimble, J. 1994. GLP-1 is localized to the mitotic region of the C. elegans germ line. Development 120: 2901-2911.

De Moor, C. and Richter, J. 2001. Translational control in vertebrate development. In Cell lineage specification and patterning of the embryo (eds. L.D. Etkin and K.W. Jeon), pp. 567-608. Academic Press, San Diego, CA.

Diatchenko, L., Lukyanov, S., Lau, Y., and Siebert, P. 1999. Suppression subtractive hybridization: A versatile method for identifying differentially expressed genes. Methods Enzymol. 303: 349-380.

Di Fruscio, M., Chen, T., Bonyadi, S., Lasko, P., and Richard, S. 1998. The identification of two Drosophila KH domain proteins: KEP1 and SAM are members of the Sam68 fam ily of GSG domain proteins. J. Biol. Chem. 273: 3012230130.

Draper, B., Mello, C., Bowerman, B., Hardin, J., and Priess, J. 1996. MEX-3 is a KH domain protein that regulates blastomere identity in early C. elegans embryos. Cell 87: 205-216.

Fire, A., Xu, S., Montgomery, M., Kostas, S., Driver, S., and Mello, C. 1998. Potent and specific genetic interference by double-stranded RNA in Caenorhabditis elegans. Nature 391: 806-811.

Francis, R., Barton, M., Kimble, J., and Schedl, T. 1995a. gld-1, a tumor suppressor gene required for oocyte development in Caenorhabditis elegans. Genetics 139: 579-606.

Francis, R., Maine, E., and Schedl, T. 1995b. Analysis of multiple roles of gld-1 in germline development: Interactions with the sex determination cascade and the $g 1 p$-1 signaling pathway. Genetics 139: 607-630.

Fraser, A.G., Kamath, R.S., Zipperlen, P., Martinez-Campos, M., Sohrmann, M., and Ahringer, J. 2000. Functional genomic analysis of $C$. elegans chromosome $I$ by systematic RNA interference. Nature 408: 325-330.

Gibson, T., Rice, P., Thompson, J., and Heringa, J. 1993. KH domains within the FMR1 sequence suggest that fragile $\mathrm{X}$ syndrome stems from a defect in RNA metabolism. Trends Biochem. Sci. 18: 331-333.

Gonczy, P., Echeverri, G., Oegema, K., Coulson, A., Jones, S.J., 
Copley, R.R., Duperon, J., Oegema, J., Brehm, M., Cassin, E., et al. 2000. Functional genomic analysis of cell division in $C$. elegans using RNAi of genes on chromosome III. Nature 408: 331-336.

Grant, B. and Hirsh, D. 1999. Receptor-mediated endocytosis in the Caenorhabditis elegans oocyte. Mol. Biol. Cell 10: 43114326.

Graves, L.E., Segal, S., and Goodwin, E.B. 1999. TRA-1 regulates the cellular distribution of the tra-2 mRNA in C. elegans. Nature 399: 802-805.

Gray, N.K. and Wickens, M. 1998. Control of translation initiation in animals. Annu. Rev. Cell Dev. Biol. 14: 399-458.

Hall, D., Winfrey, V., Blaeuer, G., Hoffman, L., Furuta, T., Rose, K., Hobert, O., and Greenstein, D. 1999. Ultrastructural features of the adult hermaphrodite gonad of Caenorhabditis elegans: Relations between the germ line and soma. Dev. Biol. 212: 101-123.

Han, M., Golden, A., Han, Y., and Sternberg, P. 1993. C. elegans lin-45 raf gene participates in let-60 ras-stimulated vulval differentiation. Nature 363: 133-140.

Hodgkin, J. and Martinelli, S. 1999. 1999 Genetic map of Caenorhabditis elegans. Caenorhabditis Genetics Center, St. Paul, MN.

Hunter, C.P. and Kenyon, C. 1996. Spatial and temporal controls target pal-1 blastomere-specification activity to a single blastomere lineage in C. elegans embryos. Cell 87: 217-226.

Jan, E., Motzny, C.K., Graves, L.E., and Goodwin, E.B. 1999. The STAR protein, GLD-1, is a translational regulator of sexual identity in C. elegans. EMBO J. 18: 258-269.

Jones, A.R. and Schedl, T. 1995. Mutations in gld-1, a female germ cell-specific tumor suppressor gene in Caenorhabditis elegans, affect a conserved domain also found in Src-associated protein Sam68. Genes \& Dev. 9: 1491-1504.

Jones, A.R., Francis, R., and Schedl, T. 1996. GLD-1, a cytoplasmic protein essential for oocyte differentiation, shows stageand sex-specific expression during Caenorhabditis elegans germline development. Dev. Biol. 180: 165-183.

Kadyk, L.C. and Kimble, J. 1998. Genetic regulation of entry into meiosis in C. elegans. Development 125: 1803-1813.

Kelly, W.G., Xu, S., Montgomery, M.K., and Fire, A. 1997. Distinct requirements for somatic and germline expression of a generally expressed Caenorhabditis elegans gene. Genetics 146: $227-238$.

Kimble, J. and Sharrock, W.J. 1983. Tissue-specific synthesis of yolk proteins in Caenorhabditis elegans. Dev. Biol. 96: 189196.

Lewis, H., Musunuru, K., Jensen, K., Edo, C., Chen, H., Darnell, R., and Burley, S. 2000. Sequence-specific RNA binding by a Nova KH domain: Implications for paraneoplastic disease and the fragile X syndrome. Cell 100: 323-332.

Maeda, I., Kohara, Y., Yamamoto, M., and Sugimoto, A. 2001. Large-scale analysis of gene function in Caenorhabditis elegans by high-throughput RNAi. Curr. Biol. 11: 171-176.

Mickey, K., Mello, C., Montgomery, M., Fire, A., and Priess, J. 1996. An inductive interaction in 4-cell stage C. elegans embryos involves APX-1 expression in the signalling cell. Development 122: 1791-1798.

Musco, G., Stier, G., Joseph, C., Castiglione Morelli, M., Nilges, M., Gibson, T., and Pastore, A. 1996. Three-dimensional structure and stability of the KH domain: Molecular insights into the fragile X syndrome. Cell 85: 237-245.

Nabel-Rosen, H., Dorevitch, N., Reuveny, A., and Volk, T. 1999. The balance between two isoforms of the Drosophila RNA-binding protein how controls tendon cell differentiation. Mol. Cell 4: 573-584.

Olsen, P. and Ambros, V. 1999. The lin-4 regulatory RNA con- trols developmental timing in Caenorhabditis elegans by blocking LIN-14 protein synthesis after the initiation of translation. Dev. Biol. 216: 671-680.

Ostareck, D., Ostareck-Lederer, A., Shatsky, I., and Hentze, M. 2001. Lipoxygenase mRNA silencing in erythroid differentiation: The 3'UTR regulatory complex controls $60 \mathrm{~S}$ ribosomal subunit joining. Cell 104: 281-290.

Praitis, V., Casey, E., Collar, D., and Austin, J. 2001. Creation of low-copy integrated transgenic lines in Caenorhabditis elegans. Genetics 157: 1217-1226.

Reinke, V., Smith, H., Nance, J., Wang, J., Van Doren, C., Begley, R., Jones, S., Davis, E., Scherer, S., Ward, S., et al. 2000. A global profile of germline gene expression in C. elegans. Mol. Cell 6: 605-616.

Rouault, T.A. and Harford, J.B. 2000. Translational control of ferritin synthesis. In Translational control of gene expression (eds. N. Sorenberg, J.W.B. Hershey, and M.B. Mathews), pp. 655-670. Cold Spring Harbor Laboratory Press, Cold Spring Harbor, NY.

Sachs, A. 2000. Physical and functional interactions between the mRNA cap structure and the poly(A) tail. In Translational control of gene expression (eds. N. Sorenberg, J. W. B. Hershey and M. B. Mathews), pp. 447-465. Cold Spring Harbor Laboratory Press, Cold Spring Harbor, NY.

Salles, F. and Strickland, S. 1995. Rapid and sensitive analysis of mRNA polyadenylation states by PCR. PCR Methods Appl. 4: 317-321.

Schedl, T. 1997. Developmental genetics of the germ line. In Caenorhabditis elegans II (eds. D.L. Riddle, T. Blumenthal, B.J. Meyer, and J.R. Priess), pp. 241-269. Cold Spring Harbor Laboratory Press, Cold Spring Harbor, NY.

Schedl, T. and Kimble, J. 1988. fog-2, a germ-line-specific sex determination gene required for hermaphrodite spermatogenesis in Caenorhabditis elegans. Genetics 119: 43-61.

Sonoda, J. and Wharton, R. 2001. Drosophila brain tumor is a translational repressor. Genes \& Dev. 15: 762-773.

Sulston, J.E. and Hodgkin, J. 1988. Methods. In The nematode Caenorhabditis elegans (ed. W.B. Wood), pp. 587-606. Cold Spring Harbor Laboratory Press, Cold Spring Harbor, NY.

Thompson, S., Goodwin, E., and Wickens, M. 2000. Rapid deadenylation and Poly(A)-dependent translational repression mediated by the Caenorhabditis elegans tra-2 3' untranslated region in Xenopus embryos. Mol. Cell. Biol. 20: 21292137.

Vernet, C. and Artzt, K. 1997. STAR: A gene family involved in signal transduction and activation of RNA. Trends Genet. 13: $479-484$.

Waddle, J.A., Karpova, T.S., Waterston, R.H., and Cooper, J.A. 1996. Movement of cortical actin patches in yeast. J. Cell Biol. 132: 861-870.

Webster, P., Liang, L., Berg, C., Lasko, P., and Macdonald, P. 1997. Translational repressor bruno plays multiple roles in development and is widely conserved. Genes \& Dev. 11: 2510-2521.

Wickens, M., Goodwin, E., Kimble, J., Strickland, S., and Hentze, M. 2000. Translational control of developmental decisions. In Translational control of gene expression (eds. N. Sorenberg, J.W.B. Hershey, and M. B. Mathews), pp. 295-370. Cold Spring Harbor Laboratory Press, Cold Spring Harbor, NY.

Zhang, B., Gallegos, M., Puoti, A., Durkin, E., Fields, S., Kimble, J., and Wickens, M. 1997. A conserved RNA-binding protein that regulates sexual fates in the C. elegans hermaphrodite germ line. Nature 390: 477-484. 


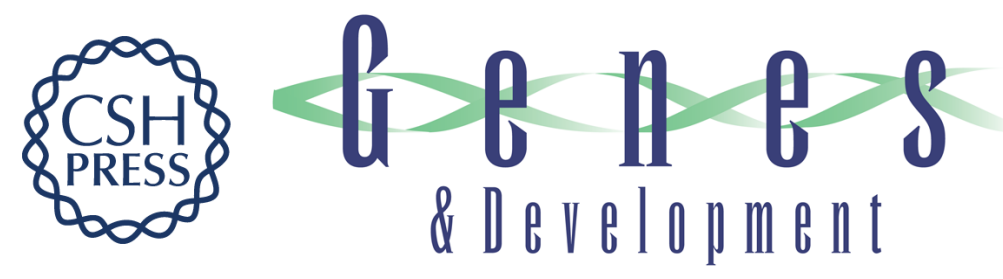

\section{Identification of in vivo mRNA targets of GLD-1, a maxi-KH motif containing protein required for $C$. elegans germ cell development}

Min-Ho Lee and Tim Schedl

Genes Dev. 2001, 15:

Access the most recent version at doi:10.1101/gad.915901

References This article cites 46 articles, 19 of which can be accessed free at:

http://genesdev.cshlp.org/content/15/18/2408.full.html\#ref-list-1

License

Email Alerting Receive free email alerts when new articles cite this article - sign up in the box at the top Service right corner of the article or click here.

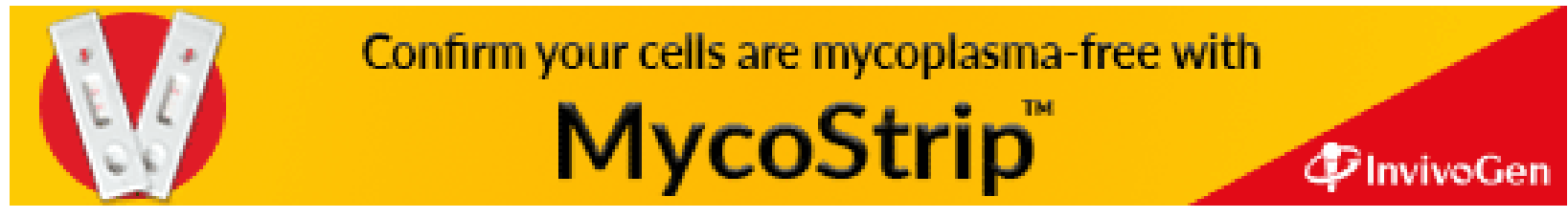

